ENTREVISTA 


\title{
Entrevista a Martin Aurell: \\ Diálogo sobre Nobleza, Matrimonio e Historiografía
}

\author{
Por Francesc Rodríguez-Bernal \\ Institut d'Estudis Medievals \\ Universitat Autònoma de Barcelona \\ 08193 Bellaterra (Barcelona). Spain \\ E-mail: i.est.medievals@uab.es
}

\section{Resumen}

Aprovechando la edición catalana de su obra Les noces du comte realizamos una entrevista al prestigioso medievalista Martin Aurell, catedrático de historia medieval en la universidad de Poitiers. A lo largo de sus respuestas, se detiene sobre problemas de historia catalana, nobleza, espiritualidad e historiografia medieval.

Palabras claye: Nobleza, mujer, matrimonio, espiritualidad, historiografja, New Medievalism.

Abstract. Interview whith Martin Aurell : Dialogues about Nobility, Mariage and Historiograpy:

Enjoying the opportunity provided by the Catalan edition of his work Les noces du comte, we interviewed the prestigious medievalist Martin Aurell, chair of Medieval History at he University of Poitiers. His responses to our questions touch on problems of Catalan history. the nobiliti, spirituality and medieval historiography.

Key words: Nobility, woman, mariage, spirituality, historiography, New Medievalism

Con motivo de la edición catalana de su obra Les noces du Comte, hemos creido oportuno realizar una entrevista al medievalista Martín Aurell, catedrático de Historia medieval en la Universidad de Poitiers y miembro del Centre d'Études Supérieures de Civilisation Médiévale. El historiador catalán (francés de adopción) ha dedicado su trayectoria científica a diversos temas: entre sus obras encontramos trabajos sobre la nobleza, la mujer en la Edad Media, las estrategias de parentesco, el mundo de los trovadores... 
Su erudición nos permitió exceder los límites de sus estudios y plantearle también algunas cuestiones de índole historiográfica, cuyas respuestas publicamos para nuestros lectores.

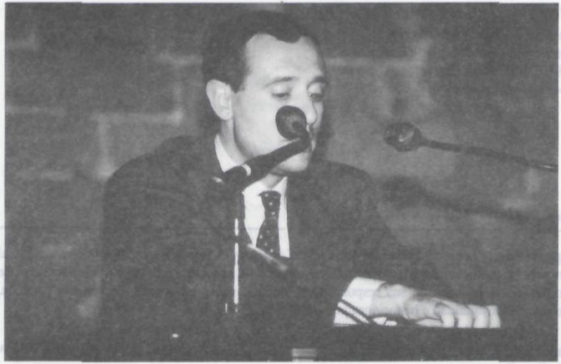

El profesor Martin Aurell i Cardona

- Nos gustaría comenzar hablando de su libro Les noces du comte, recientemente traducido a la lengua catalana'. En la sociedad subpirenáica de los siglos X y XI las mujeres afloran como verdaderas protagonistas de la escena política. La condesa Ermesenda de Carcasona llega a dirigir personalmente los tres condados más poderosos del momento: Barcelona, Girona y Osona. Pero ella es sólo la punta del iceberg: otras damas de la nobleza catalana conducen la política de sus linajes y administran sus extensos patrimonios sin graves problemas. La paulatina deterioración de las mujeres nobles a lo largo de los siglos posteriores ha sido ya estudiada por Usted en otra ocasión ${ }^{2}$. Pero ¿qué explicación pueden dar los medievalistas sobre esta súbita llegada de las mujeres a los centros de decisión política catalana en los siglos X y XI?

\footnotetext{
1 Martin AURELL, Les noces del comte. Matrimoni i poder a Catalunya (785-1213), Barcelona, Omega, 1998.

${ }^{2}$ Martin AURELL, "La déterioration du statut de la femme aristocratique en Provence (Xe - XIIle siècles)," Le Moyen Age, 1985, pp. 5-32.
} 
El fenómeno tiene raices profundas, más antiguas. La mujer ocupa una posición central en el mundo germánico, sea godo o franco, cuyas estructuras de parentesco son cognáticas e incluso matrilineales. La influencia de sus prácticas sociales perdura aún en el año mil, Pero como dice usted con acierto, la aparición de Ermesenda de Carcasona o de Almodis de la Marca en el panorama político catalán presenta un carácter súbito e inesperado. Esta irrupción se puede explicar por la privatización del poder, lo que llamamos (la expresión debe guardarse) "mutación feudal". La consolidación del sistema hereditario de las cargas condales y vicariales acarrea un carácter más doméstico, más privado, del poder público. La condesa participa entonces, gracias al consortium, de la auctoritas y la potestas de su marido. Aparece, por ejemplo, casi siempre en el protocolo o en el escatocolo de sus cartas: esta mutación diplomática no está sólo en relación con un cambio de formularios o discursos, sino que encierra una verdadera transformación política y social. El poder consorcial alcanza su máxima plenitud durante la viudez de la condesa, que acapara a la muerte de su marido un poder tan importante que su hijo se subleva a menudo contra ella para recuperar el cargo de su padre a la mayoría de edad. Esta emancipación violenta coincide con su casamiento, marcando la mayoría legal. Por eso, las relaciones entre suegra y nuera (Ermesenda contra Almodis) pueden ser $\tan$ belicosas.

En la Alta Edad Media las estrategias matrimoniales y los intercambios patrimoniales son realidades inseparables. En Cataluña, desde que el Dr. LALINDE ABADŕ A se interesase por esta temática ${ }^{3}$, no se han producido estudios relevantes que la revisen de manera general hasta la aparición de su libro. Su minucioso estudio de la documentación catalana le ha permitido, precisamente, poner de relieve la importacia de un tipo de intercambio patrimonial vinculado al matrimonio que habia sido olvidado hasta ahora: el douarie. Ahora bien: si todas estas estrategias de intercambio no obedecen a un lógica cronológica (dotes y esponsalicios, por ejemplo, son cohetáneos hasta más allá del siglo XII) ¿qué motiva la elección de uno u otro tipo de intercambio a la hora de relaizar un matrimonio?

\footnotetext{
${ }^{3}$ Jesús LALINDE ABAdi A, "Los pactos matrimoniales catalanes. Esquema historico", Amario de Historia del Derecho Español, 1963, pp. 133-266.
} 
El problema de la transición del esponsalicio (dones del marido a la esposa, que llamamos douaire en francés) a la dote (dones del padre de la esposa al marido) durante el siglo XII es capital. Este cambio determina en particular la deterioración del estatuto de la mujer puesto que transforma las estrategias matrimoniales de hipergámicas (superioridad social de la mujer) a hipogámicas (superioridad social del marido). Si la dote acaba triunfando es seguramente en razón del renacimiento del derecho romano y de la fascinación que ejerce en el legislador. $\mathrm{La}$ monetarización de los intercambios patrimoniales también favorece la dote en un sistema virilocal de matrimonio, como lo es el occidental.

- En los últimos años el papel de la nobleza en la historiografía sobre la Edad Media vuelve a resurgir con fuerza. Precisamente Usted ha realizado numerosas aportaciones al respecto ${ }^{4}$ ¿De qué manera la revisión del rol de la nobleza puede modificar nuestro conocimiento sobre la sociedad medieval?

Todo conocimiento de la sociedad medieval pasa necesariamente por un estudio profundo de la nobleza. Aunque ésta represente sólo el $5 \%$ de la población, las decisiones y comportamientos de sus miembros condicionan la evolución global. Es la clase dirigente, la élite militar y cultural, el grupo que difunde modelos de vida a las otras categorías sociales. Desde el punto de vista metodológico, es el grupo mejor documentado, el único sobre el cual se puede hacer prosopografia con precisión. A partir de él se deducen las redes de parentesco y de clientela que determinan la organización social de una Edad Media en la que el papel del estado como realidad pública e independiente es tan débil. Incluso la construcción de este estado se debe, en parte, a la participación de miembros de la nobleza en el gobierno real. Por supuesto, el sistema aristocrático, fundado sobre algo parecido a los privilegios de casta, repugna a nuestras mentalidades contemporáneas igualitarias. Pero sería ridículo transformar el trabajo del historiador en lección moral o en contestación social del pasado. Nos guste o no, es imposible comprender la Edad Media olvidando a la aristocracia.

- Siguiendo aún centrados en el papel de la nobleza. La historiografia actual parece reclamar una revisión de su rol

\footnotetext{
${ }^{4}$ Martin AURELL. Une famille de la noblesse provençale au Moyen Age: Les porlelet, Avignon, Aubanel-Distic, 1986. También La vieille et l'épée. Troubadours et politique es Provence au XIIJe siècle, Paris, Aubier, 1989. Más recientemente La noblesse en Occident (Ve-XVe siècles). Paris, Armand Colin, 1996.
} 
social. No sólo debe mantenerse su imagen tópica de guerreros y defensores ante el otro, sino que hay que rescatar del olvido su papel como administradores de rentas y patrimonios. Ante la tradicional representación de la aristocracia como básicamente rural y resistente a los cambios, ¿puede dibujarse una nueva imagen del noble como económicamente más activo, dinámico y urbano que nos ayude a superar los tópicos anteriores?

En los países mediterráneos la nobleza es esencialmente urbana. Constituye un verdadero patriciado que acaparó en la Alta Edad Media la defensa militar de su ciudad, verdadera fortaleza durante las invasiones y que participó luego en las luchas intestinas del año mil. Los combates entre los condes y los vizcondes de Barcelona del siglo XI son célebres. Con la pacificación de la sociedad y el triunfo del movimiento comunal en el siglo XIII, el estatuto de este patriciado militar cambia radicalmente. Se transforma en un orden que proporciona parte personal político y militar al Estado moderno en gestación. Los nobles desprecian sin embargo las actividades mercantiles. Los nuevos ricos que quisieran integrarse en este grupo, en un ambiente que a pesar de sus rigideces jerárquicas presenta una gran movilidad social, habrán de transformar sus ganancias en renta, adoptando un género de vida hecho de otium en lugar de negotium. Su "capital material" se convierte asi en "material simbólico", hecho de prestigio, honor y fama. En Barcelona, esta aristocratización de los mercaderes explica la decadencia de la ciudad bajo los Habsburgo.

- En una sociedad como la contemporánea, las nuevas generaciones de historiadores tienden a olvidar el papel que los fenómenos religiosos, espirituales, tuvieron para los hombres y mujeres del Medievo, y ocupan un lugar marginal en la actual producción historiográfica. Ante ellos, usted ha mostrado recientemente cómo la monarquía catalanoaragonesa de la Baja Edad Media era una gran consumidora de literatura apocalíptica hasta el punto de determinar su creación de una imagen propia ante el resto de la cristiandad ${ }^{5}$. ¿Cómo puede la revisión de este tipo de estudios ayudarnos a comprender mejor a las sociedades medievales?

\footnotetext{
5 "Messianisme royal de la Couronne d'Aragon (XIVe - XVe siècle.)", Annales, Histoire Sciences Sociales, 1997, pp. 119-155.
} 
En Francia no existe actualmente prejuicio alguno contra la historia religiosa en los jóvenes medievalistas, de horizontes personales o filosóficos muy hetereóclitos. En los tres últimos años, casi la mitad de las tesis de doctorado que se han leído en nuestro campo en este país tratan de espiritualidad o religiosidad. André VAUCHEZ, en la actualidad director de I'Ecole Française de Rome, ha contribuido mucho a esta renovación con su seminario y su grupo de doctorandos, muchos de ellos provenientes de l'École Normale Supérieure. Al margen de esta estructura universitaria tradicional, Jacques LE GOFF, Jean-Claude SCMITT o Alain BOUREAU, medivalistas de l'École des Hautes Etudes en Sciences Sociales, han publicado sendos libros sobre el purgatorio, sobre los espíritus de los muertos o sobre el discurso cristiano del tiempo. Se podría decir lo mismo de Italia, donde nuestro conocimiento sobre temas tan diversos como los estigmas de San Francisco o los pecados de la lengua han dado lugar a libros apasionantes. De hecho, si existe actualmente retraso en este dominio en las universidades ibéricas, es porque tradicionalmente las investigaciones de historia religiosa se confiaban a universidades de teología o a eclesiásticos. Pero seguramente Cataluña conocerá la misma evolución que Francia o Italia en las próximas décadas. La historia religiosa se enmarcará asi en una historia total que no olvidará la dimensión política o social de la espiritualidad de la Edad Media.

- Del otro lado del atlántico están llegando los trabajos realizados por los medievalistas estadounidenses del denominado "new medievalism". Con un discurso que aboga esencialmente por una reinterpretación de las metodologías de la historia medieval, cobran poco a poco fuerza, en un contexto historiográfico europeo que se percibe de desorientación. ¿Cómo cabe valorar este movimiento intelectual y de qué manera pueden, los estudiosos de la vieja Europa, ayudar a definir el camino de la historiografia medieval del próximo milenio?

La historiografia estadounidense más progresista está actualmente fascinada por lo excepcional, lo grotesco o monstruoso de la civilización medieval. Esta percepción tan fuerte de la alteridad se explica por un cambio -una verdadera revolución mental- de los medievalistas americanos a partir de 1968. Rechazaron entonces sus raíces culturales europeas, contrariamente a la generación precedente que estudiaba la Edad Media occidental como el lugar en que se forjaron los valores (por ejemplo de libertad comunal) en los que echó raíces el nuevo mundo. La 
historiografia americana actual nos enseña una cierta intrepidez intelectual, la osadía de cuestionar las fuentes con originalidad, una mirada etnológica sobre nuestro pasado. También admiro en ella su precisión estadística. Sin embargo, lo que nos une a la historiografia americana es mucho más importante de lo que nos separa de ella. Ambos participamos del mismo movimiento de renovación historiográfica. No creo que el contexto europeo esté desorientado, sino más bien lleno de vitalidad, lo que explica la imagen de confusión aparente que da, imagen de ausencia de escuelas y de gran variedad metodológica. Pero esto es prueba de dinamismo. De todas formas, el diálogo entre historiadores existe mucho más que en las otras ciencias humanas, cuya epistemología no presenta la unidad de la nuestra, fundada sobre reglas de erudición claramente definidas desde el siglo XVII.

- A lo largo del camino de la producción histórica, los especialistas conciben ocasionalmente formulaciones conceptuales que, susceptibles de una cierta generalización, resultan de gran utilidad para el quehacer histórico. Así, elementos tales como "el terror del año mil", "la reconquista" o la "devotio moderna" han sido suficientes para crear imágenes de un momento del pasado medieval hasta definirlo. En la actualidad la historiografia europea sigue debatiendo acaloradamente en torno a otra de estas formulaciones: "la revolución del año mil". El debate, sin embargo, está lejos de haberse solucionado ${ }^{7}$, pues a la tesis de Guy Bois se le han aducido también algunos problemas de método. ¿Qué posición permite adoptar la abundante documentación catalana ante el fenómeno de la "mutation de l'an mil"?

La negación de la mutación del año mil es un fenómeno marginal en el medievalismo actual, que ha intervenido desgraciadamente en un ambiente más de polémica que de debate. Pero el interés de sus cuestiones ha permitido profundizar nuestros métodos y nuestra escritura de la historia. Una cosa es innegable: la privatización del poder, la aparición de linajes de condes y vicarios independientes existe en los

\footnotetext{
6 Desafortunadamente traducida en España por la "revolución del año mil". La obra ha sido repetidamente reeditada. Recientemente Josep Maria SALRACH to ha hecho en Guy BOIS, La revolución del año mil, Grijalbo-Mondadori, 1997

7 Entre sus detractores más combativos se encuentra Dominique BARTHÉLEMY, que ha publicado recientemente la obra La mutation de l'an mil a-t-elle eu lieu, Paris, Fayard, 1997.
} 
siglos X y XI, aunque por supuesto las modalidades y la cronología de este fenómeno varían según las regiones. La cualidad excepcional de la documentación diplomática catalana (desgraciadamente no podemos decir lo mismo de nuestra pobre historiografia anterior al siglo XII) permite demostrar que el cambio perceptible hacia el año mil no se debió sólo a nuevas formas de expresión, a un nuevo discurso de los escribas que falsearía nuestra percepción, a una "revelación" documental más que a una "revolución" social. Los archivos catalanes nos informan con precisión sobre el aumento de los castillos, dato corroborado por la arqueología, sobre la aparición de señoríos jurisdiccionales, sobre la deterioración del estatuto de los campesinos con los consiguientes mals usos, sobre la aparición de guerras privadas contestando al poder condal, sobre la ascensión social de los milites o caballeros de las guardias castrales... ¿si eso no es una revolución social, qué es? 


\section{MARTIN AURELL I CARDONA}

Barcelona, España, 23 de Febrero de 1958.

\section{Formación}

Col.legi Viaró, Sant Cugat del Vallès. España.

Facultat d'Història i Geografia, Universitat de Barcelona. España.

Maîtrise de Historia Medieval y Licence de Lingüistica en Université Aix-Marsella I, Francia, en 1979.

Doctorado de tercer ciclo en Aix-Marsella I, Francia, 1983.

Diploma de l'École Pratique des Hautes Études, Paris, Francia, en Ciencias Históricas y Filológicas en 1989.

Doctorado d'État en Aix-Marsella I, Francia, en 1994.

\section{Trayectoria}

Assistant de Historia Medieval en la Universidad de Niza, Francia, 19851987

Copeland Fellow en Amherst College, Massachusetts, Estados Unidos, 1987.

Maître de Conférences de Historia Medieval en la Universidad de Rouen, Francia, 1988-1992.

Maître de Conférences de Historia Medieval en la Universidad de Paris IV-Sorbona, 1992-1994.

Professeur de Historia Medieval en la Universidad de Poitiers desde 1994.

\section{Bibliografía}

\section{Libros}

Une famille de la noblesse provençale au Moyen Âge: Les Porcelet, Avignon, Aubanel-Distic, 1986. 
La vielle et l'épée. Troubadours et politique en Provence au XIIIe siècle, Paris, Aubier, 1989.

Les noces du comte. Mariage et pouvoir en Catalogne (785-1213). Paris, Publications de la Sorbonne, 1995. (Traducción Catalana en Barcelona, Ediciones Omega, 1998.)

La noblesse en Occident (Ve - XVe siècle), Paris, Armand Colin, 1996.

Actes de la famille Porcelet (972-1320), Paris, Comité des Travaux Historiques et Scientifiques, Collection des Documents Inédits de l'Histoire de France (En prensa)

\section{Principales articulos}

"Le personnel politique catalan et aragonais en Provence sous Alphonse ler (1162-1196)", Annales du Midi, 1981, pp. 121-139.

"Els fonaments socials de la dominació catalana a Provença sota Alfons el Cast (1166-1196)", Acta Historica et Archaeologica Medievalia, 1984-1985, pp. 83-110.

"La déterioration du statut de la femme aristocratique en provence (XeXIIle siècle)", Le Moyen Age, 1985, pp. 5-32.

"L'expansion catalane en Provence au XIle siècle", La formació $i$ l'expansió del feudalisme català. Estudi General, Girona, 1986, pp. 175-197.

"Les cisterciens et leurs protecteurs en Provence rhodanienne", Cahiers de Fanjeaux, 1986, pp. 235-267.

"Le lignage aristocratique en Provence au XI siècle", Annales du Midi, 1986, pp. 149-163.

"Chevaliers et chevalerie chez Raymond Lulle", Cahiers de Fanjeaux, 1987, pp. 141-157.

"Autour d'un débat historiographique: l'expansion catalane dans les pays de langue d'oc au Moyen Age", Montpellier, la Courone d'Aragon et les pays de langue d'Oc au Moyen Age, Montpellier, 1987, pp. 9-41.

"Le troubadour Bertran de Lamanon (c. 1210-1270) et les luttes de son temps", Boletín de la Real Academia de Buenas Letras de Barcelona, 1987-1988, pp. 121-162. 
"Pouvoir et contre-pouvoirs en Rouerge sous la domination catalane (1162-1204)", Libertés locales et vie municipale en Rouergue, Languedoc et Roussillon, Montpellier, 1988, pp. 127-136.

"Ghibelinism, Valdeism or licenciousness? The Troubadours of Provence against the Church (1245-1282)", Comunicación al Congreso The Medieval Institute (Kalamazoo, 7-10 mai 1987). Traducción italiana "I trovatori provenzali contra il clero", Storia e dossier, junio 1989, pp. 34-38.

"Autour de l'identité héraldique de la noblesse provençale au XIIIe siècle", Médiévales, automne 1990, pp. 17-28.

"Prophétie et messianisme politique. La Péninsule Ibérique au miroir du Liber Ostensor de Jean de Roquetaillade", Mélanges de l'École Française de Rome, 1990, pp. 317-361.

"Jalons pour une enquête sur les stratégies matrimoniales des comtes catalans (IXe - Xle siècle)", Symposium internacional sobre els origens de Catalunya (Segles VIII-XI), Barcelone, 1991, T. 1, pp. 281-364.

"Eschatologie, spiritualité et politique dans la confédération catalanoaragonaise (1282-1412)", Cahiers de Fanjeaux, 1992, pp. 191-235.

"La fin du monde, l'enfer et le roi: une prophétie catalane du XVe siècle", Revue Mabillon, 1994, pp. 143-177

"Nécropoles et donats: les comtes de la maison de Barcelone et l'Hôpital (XIIe - XIIIe siècles)", Provence Historique, 1995, pp. 7-24.

"Messianisme royal de la Couronne d'Aragon (XIVe-XVe siècle.)", Annales, Histoire, Sciences Sociales, 1997, pp. 119-155.

"La Chevalerie urbaine en Occitanie (fin Xe - début XIIIe siècle)", Les élites urbaines au Moyen Age. Actes du colloque de la S.H.M.E.S.P., Rome, Ralais Farnese 23-25, mai 1996, Paris-Roma, Publications de la Sorbonne-École Française, 1997, pp. 71-118.

"La noblesse occidentale à la fin du Moyen Age: bilan histoirographique et perspectives de recherche", Memoria y Civilización. Anuario de Histoira, 1998, p. 97-110. Traducción Inglesa en Nobles \& Nobility in Medieval Europe (King's College London, 15-17 April 1998).

"Prédication, croisade et religion civique. Vie et miracles de l'évêque Oleguer (+1137) de Barcelone", Revue Mabillon (En prensa). 


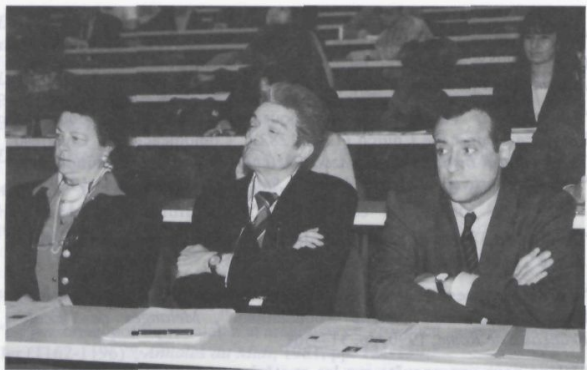

Miembro de Instituciones

Secretario adjunto de la Société des Médiévistes de l'Enseignement Supérieur Public, 1992-1995.

Comité National des Universités (Sección 21), desde 1995.

Consejo del Centre d'Études Supérieures de Civilisation Médiévale de l'Université de Poitiers desde 1995.

Délegation Permanente de la Commision Nationale de l'Inventaire Général des Monuments et des Richesses Artistiques de la France, desde 1995.

Correspondiente de la Reial Acadèmia de Bones Lletres de Barcelona, desde 1996.

Société des Antiquaires de l'Ouest, desde 1998.

\section{Distinciones}

Medalla de la Ciudad de Arles, 1988.

Premio "Bohus-Szögyény " de la Confederación Internacional de Genealogía y Heráldica, 1998. 